\title{
UPAYA KONVERGENSI TELEVISI LOKAL MELALUI PROGRAM BERITA BERBAHASA LOKAL \\ ( Kajian Terhadap Program Berita JTV : \\ Pojok Kampung, Pojok Medhureh, dan Pojok Kulonan \\ menggunakanCommunication Accomodation Theory-CAT)
}

\author{
Andiwi Meifilina \\ Program Studi Ilmu Komunikasi Fakultas Ilmu Sosial dan Ilmu Politik \\ Universitas Islam Balitar Blitar \\ Email: andiwimeifilina@unisbablitar.ac.id
}

\begin{abstract}
The phenomenon of the existence of the mass media through which the local television program for viewers to give plenty of options in accordance with the language and culture of each as well as a means of communication to understand the language of different cultures within a single province. JTV stands for Java Pos Television merpakan largest local television station in East Java Province and is the first local television in Indonesia which was established as a locally based broadcasters with the cultures of East Java are highly diverse. There are several languages used as languages of East Java community Suroboyoan wetanan inherent in citizens of Surabaya, Sidoarjo, Malang and Mojokerto. Further languages are attached to the Madurese community Pasuruan, Probolinggo, Jember and Lumajang and Mataraman Java language that is identical to the citizens of East Java Kulonan Blitar, Tulungagung, Kediri and Madiun.JTV accommodate the different variety of language through news programs' Corner Village (Suroboyoan language), corner Medhureh (Madura language), corner Kulonan (Javanese Kromo).
\end{abstract}

Key Words: local television, local language, news program 


\section{PENDAHULUAN}

Berawal dari sebuah tesis bahwa fenomena komunikasi antar budaya tidak hanya terjadi di lintas benua, antar negara dan antar pulau saja, tetapi juga banyak terjadi di depan mata dan disekitar tempat tinggal kita sendiri. Penulis yang notabennya lahir dan berdomisili di Jawa Timur menangkap suatu fenomena komunikasi antar budaya yang memiliki keunikan untuk dijadikan bahan kajian. Fenomena ini lahir dari keberadaan suatu media massa yakni televisi lokal yang melalui program-programnya memberi banyak pilihan bagi para pemirsanya sesuai dengan bahasa dan budaya masing-masing, sekaligus sebagai sarana komunikasi untuk bisa memahami berbagai bahasa dari budaya yang berbeda dalam lingkup satu propinsi. Jawa Pos Media Televisi atau kepanjangan dari JTV adalah salah satu stasiun televisi lokal terbesar yang berada di propinsi Jawa Timur dan televisi swasta regional pertama di Indonesia. JTV didirikan sebagai lembaga penyiaran berbasis lokal dengan kultur budaya Jawa Timur yang sangat beraneka ragam dan sangat melekat.

Seperti diketahui, ada beberapa bahasa yang digunakan oleh warga masyarakat Jawa Timur. Bahasa Suroboyoan yang sangat lekat dengan warga wetanan yakni Surabaya, Sidoarjo, Malang dan Mojokerto. Selanjutnya ada bahasa Madura yang identik digunakan oleh masyarakat Jawa Timur yang biasa disebut kawasan tapal kuda, yakni Pasuruan, Probolinggo, Lumajang dan Jember, serta bahasa Jawa Mataraman yang identik dengan warga Jatim kulonan yakni Blitar, Tulungagung, Kediri dan Madiun. JTV sebagai televisi lokal ternyata mencoba mengakomodasi ragam bahasa yang berbeda itu melalui beberapa program berita, yakni Pojok Kampung (berita menggunakan bahasa Suroboyoan), Pojok Medhureh (berita dalam Bahasa Madura), dan Pojok Kulonan (berita dalam Bahasa Jawa Kromo).

Keberadaan dan tersajinya program-program berita dengan tiga bahasa lokal Jawa Timur itu bukan tanpa hambatan. Bahasa Suroboyoan yang lugas, spontan dan ceplas-ceplos, bagi sebagian warga jatim kulonan terdengar sangat kasar. Misalnya saja dalam program berita Pojok Kampung yang oleh presenter disampaikanLanangan enom ditemokno matek dilindes truk. Bagi warga 
Surabaya, kalimat dan bahasa tersebut sudah dianggap biasa dan wajar, namun bagi warga jatim kulonan, kalimat itu dinilai sangat kasar. Warga yang tidak nyaman mendengar berita dengan bahasa suroboyoan, bisa saja mematikan televisi atau memindah Channel. JTV peka terhadap fenomena tersebut dan memberi pilihan program Pojok Kulonan yang menggunakan bahasa lebih halus dan terkesan sopan, meskipun isi berita sama. Begitu juga dengan Pojok Medhureh yang menyajikan bahasa Madura. Disinilah Komunikasi antar budaya terjadi, ketika ada masyarakat yang berusaha bertahan dengan menonton berita yang menyajikan bahasa berbeda dengan yang biasa digunakan di wilayah tempat tinggalnya. Misalnya warga jatim kulonan yang tetap setia menonton Pojok Kampung dan berusaha untuk belajar memahami bahasa wetanan. Begitu juga sebaliknya warga Surabaya yang tetap menonton Pojok Kulonan sembari belajar memahami bahasa kromo halus. Ini adalah hal yang unik karena terjadi pada lingkup satu propinsi yang secara geografis sangat dekat.

Untuk mengkaji fenomena diatas, penulis mencoba untuk mencari keterkaitan atau titik singgung antara media massa dan komunikasi antar budaya, dengan menggunakan pisau bedah teori komunikasi akomodasi atau Communication Accomodation Theory yang biasa di sebut CAT. Teori ini digagas oleh Howard Giles, seorang professor ilmu komunikasi dari Universitas Santa Barbara California pada tahun 1971. Giles memperkenalkan konsep Konvergensi yang menggambarkan proses dimana individu melakukan peralihangaya bicara atau bahasa untuk menyamakan dirinya dengan orang-orang yang berinteraksi dengan mereka. Giles berpendapat bahwa seorang penutur (komunikator) akan berusaha meminimalkan adanya perbedaan sosial dengan lawan bicara (komunikan).

Ketika JTV yang juga milik Jawa Pos Grup ini didirikan di wilayah Jawa Timur, maka JTV berusaha untuk mengakomodasi bahasa-bahasa lokal Jawa Timur ke dalam program-program nya, meskipun sebenarnya JTV juga memiliki afiliasi dengan Malioboro TV (Yogyakarta), PJTV (Padjajaran TV) (Bandung), dan Jak TV (Jakarta).Penulis dalam hal ini memposisikan JTV sebagai komunikator yang menyampaikan pesan (berita) kepada pemirsa sebagai 
komunikan. Konsistensi JTV sebagai televisi lokal yang mengakomodasi kultur dan budaya setempat juga terbukti dengan tayangan-tayangan film luar negeri yang di alih bahasakan ke bahasa Jawa. Film India disajikan dan dialih bahasanya ke bahasa jawa. Film Korea juga demikian. Bahkan Siaran berita bahasa Suroboyoan Pojok Kampung JTV pernah meraih penghargaan dari Surabaya Heritage sebagai salah satu pusaka bangsa. Program andalan televisi berslogan Satus Persen Jatimtersebut dinilai sangat melestarikan bahasa Suroboyoan.

Konvergensi yang dilakukan oleh JTVbukan tanpa pro kontra. Ketika Pojok Kampung tayang, warga jatim kulonan menyatakan keberatan dan menyampaikan protes, namun JTV tetap berupaya bijaksana dengan memberikan pilihan sesuai bahasa lokal masing-masing. Hal inilah yang akan dibahas dalam essay ini. Apakah program yang ditawarkan bisa meminimalkan konflik yang mungkin akan timbul dintara masyarakat.Apakah konvergensi yang dilakukan JTV bisa memperluas cakrawala komunikasi antar budaya dan bagaimana konsistensi sebuah televisi lokal ketika terbentur dengan beraneka ragam budaya lokal. Tema dan judul essay ini dipilih oleh penulis sesuai dengan kerangka kajian komunikasi antar budaya, yakni membahas dinamika dalam proses komunikasi dengan memperhatikan faktor budaya dari para pelaku dan lingkungan budaya pada suatu aktivitas kegiatan komunikasi, menempatkan proses komunikasi pada interaksi antarmanusia dengan beragam latar belakang budaya.

\section{Pentingnya Bahasa dalam Komunikasi Antarbudaya}

Bahasa merupakan inti dari interaksi manusia, yang sangat memungkinkan manusia untuk saling bertukar pandangan serta bisa menyampaikan budaya satu ke budaya yang lainBenjamin Lee Whorf mengatakan bahwa bahasa mampu membentuk pola pikir kita dan menentukan apa yang kita pikirkan.Melalui bahasalah manusia belajar tentang nilai, perilaku dan identitas. Bahasa merupakan aspek yang penting dalam belajar komunikasi antar budaya. Penggunaan bahasa terjadi setiap hari pada setiap orang di seluruh dunia. Berbicara dengan teman, mendengarkan musik, menonton televisi, menjelajahi internet, semua memerlukan bahasa. Bahasa juga digunakan untuk menyatakan identitas. Dialek dan aksen menjadi bagian identitas seseorang. Pada dasarnya bahasa ialah sejumlah simbol 
atau tanda yang disetujui untuk digunakan oleh sekelompok orang untuk menghasilkan arti atau makna.

Terdapat simbiosis yang erat antara bahasa dan budaya. Keduanya bekerjasama dalam hubungan yang saling menguntungkan yang menjamin keberadaan dan kelangsungan keduanya. Untuk memiliki suatu budaya, bahasa dibutuhkan, sehingga anggota suatu kelompok dapat berbagi kepercayaan, nilai, dan perilaku dan terlibat dalam usaha komunal. Sebaliknya, budaya dibutuhkan untuk mengatur pribadi yang berlainan ke dalam kelompok yang utuh, sehingga kepercayaan, nilai, perilaku dan aktivitas komunitas dapat terbangun.Penulis setuju dengan pernyataan Salzmann bahwa budaya manusia dengan segala kerumitannya tidak akan bisa teratasi tanpa bantuan bahasa.

Penulis menggunakan istilah komunikasi antarbudaya, sebab penulis berpendapat istilah ini lebih tepat, karena dalam komunikasi antar penutur yang berbeda latar belakang budayanya, maka pola komunikasi yang terbentuk merupakan satu pola baru sebagai sinergi pola komunikasi penutur dengan mitra tutur. Komunikasi antarbudaya pada dasarnya mengkaji bagaimana budaya berpengaruh terhadap aktivitas komunikasi, apa makna pesan verbal dan non verbal menurut budaya-budaya yang bersangkutan, apa yang layak dikomunikasikan, kapan mengkomunikasikannya,bagaimana cara mengkomunikasikannya. Ketika komunikasi terjadi antara orang-orang berbeda bangsa, agama, kelompok ras, atau kelompok bahasa, komunikasi itu disebut komunikasi antarbudaya.

Ketika memasuki wilayah orang lain maka akan dihadapkan dengan orangorang yang sedikit banyak berbeda dalam berbagai aspek (sosial, budaya, ekonomi, status,dan lain-lain). Secara khusus fungsi komunikasi antarbudaya adalah untuk mengurangi ketidakpastian.Pada waktu itu pula kita dihadapkan dengan ketidakpastian dan ambiguitas dalam komunikasi.

Unsur lokalitas yang disuguhkan JTV, mengingatkan betapa bahasa yang berbeda bisa dipelajari dan dipahami melalui tayangan televisi.JTV berupaya menjalankan peran dan fungsi media secara baik, dimana salah satu fungsi media adalah fungsi edukasi, mendidik masyarakat untuk saling menghargai budaya 
lain.Membicarakan mengenai pentingnya bahasa, JTV menangkap hal ini dengan peka dan menempatkan beberapa program berita berbahasa lokal sesuai dengan tempat dimana JTV berada. Jika budaya melalui bahasa itu bisa dipelajari, sikap etnosentris, stereotipe dan konflik antar etnis tidak perlu terjadi.

\section{Peran Media Televisi dalam Komunikasi antarbudaya}

Banyak pilihan program berita yang disajikan dengan bahasa-bahasa yang berbeda dengan tujuan agar pemirsa di Jawa Timur khususnya, bisa menangkap isi dan pesan yang disampaikan melalui program berita.Mencermati poin keempat dan ke-lima pada kalimat di atas, dimana media dan budaya memiliki keterkaitan dan hubungan yang erat dalam menyatukan komunikasi, maka apa yang disuguhkan televisi dalam hal ini JTV merupakan sesuatu yang menarik. Dibanding televisi swasta nasional yang lebih banyak menggunakan bahasa Indonesia, ataupun jika memiliki program yang memiliki unsure budaya maka akan menampilkan secara beragam dari seluruh pelosok Indonesia. Tetapi JTV memanjakan pemirsa yang ada di Jawa Timur, karena selain sebagai televisi lokal, JTV merasa memiliki tanggung jawab untuk menawarkan pilihan program yang mengakomodir banyak bahasa di dalamnya. Dan ini sudah diwujudkan dalam program berita Pojok Kampung, Pojok Medhureh, dan Pojok Kulonan.

Sebagai sebuah stasiun televisi lokal Jawa Timur, JTV menyesuaikan program-programnya dengan masyarakat Jawa Timur. Mengulas tentang program inovatif, JTV merupakan salah satu contoh stasin televisi swasta lokal yang menampilkan program inovatif dengan program-program berbahasa daerah.JTV sendiri berupaya untuk dekat dengan masyarakat Jawa Timur, terutama masyarakat Surabaya yang menjadi target audience utamanya, dengan menggunakan bahasa-bahasa yang sering digunakan oleh masyarakat Surabaya, yaitu Bahasa Suroboyoan. Namun, usaha JTV untuk lebih dekat dengan pemirsanya ternyata menuai kontroversi. Sebagian besar masyarakat Surabaya malahan tidak setuju dengan penggunaan Bahasa Suroboyoan dalam programprogram JTV yang dianggap terlalu vulgar (JTV Sepakati, 2005). JTV mencoba untuk megusahakan feedback positif dari masyarakat dengan menayangkan 
program-program Bahasa Suroboyoan dalam format yang bervariasi.Walaupun menuai kontroversi dengan program-program ber-Bahasa Suroboyoan, JTV tetap mempertahankan ciri khasnya tersebut.

\section{Communication Accomodation Theory (CAT)dan Strategi Konvergensi JTV}

Howard Giles, seorang profesor ilmu komunikasi dari Universitas California pada tahun 1971 menggagas tentang CAT atauCommunication Accomodation Theory. Giles berpendapat bahwa seorang penutur (komunikator ) akan berusaha meminimalkan adanya perbedaan sosial dengan lawan bicara (komunikan). Giles memperkenalkan konsep Konvergensi yang menggambarkan proses dimana individu melakukan pergeseran gaya bicara atau bahasa untuk menjadi seperti orang-orang dengan siapa mereka berinteraksi.

Ketika JTV yang juga milik Jawa Pos Grup ini didirikan di wilayah Jawa Timur, maka JTV berusaha mengakomodasi bahasa-bahasa lokal Jawa Timur dalam program-program nya, meskipun sebenarnya JTV juga memiliki afiliasi dengan Malioboro TV (Yogyakarta), PJTV (Padjajaran TV) (Bandung), dan Jak TV (Jakarta). Dalam hal ini penulis memposisikan JTV sebagai komunikator yang menyampaikan pesan (berita) kepada pemirsa sebagai komunikan. Konsistensi JTV sebagai televisi lokal yang mengakomodasi kultur dan budaya setempat juga terbukti dengan tayangan-tayangan film luar negeri yang di alih bahasakan ke bahasa Jawa. Film India disajikan dan dialih bahasa ke bahasa jawa. Film Korea juga demikian. Program andalan televisi berslogan Satus Persen Jatim tersebut dinilai melestarikan bahasa Suroboyoan.Bahkan Siaran berita bahasa Suroboyoan Pojok Kampung JTV sebagai salah satu pusaka bangsadan meraih penghargaan dari Surabaya Heritage.

Identitas telah digambarkan sebagai satu set ide tentang keanggotaan kelompok etnis seseorang, termasuk identifikasi diri dan pengetahuan tentang budaya, tradisi, kebiasaan, nilai, dan perilaku. Identitas pribadi mengacu pada karakteristik unik individu, terlepas dari kelompok budaya atau sosial, sedangkan identitas sosial didefinisikan sebagai pengetahuan seseorang tentang keanggotaan dalam kelompok sosial tertentu dan makna sosial yang melekat pada kelompok 
tersebut.Kajian komunikasi antarbudaya telah mengakui pentingnya identitas dalam penelitian antarbudaya. Secara khusus, teori akomodasi komunikasi (CAT) menyatakan bahwa bahasa dan pidato (serta penanda komunikatif lainnya, seperti pakaian, rumah, artefak, tato, festival, pawai, dan lain-lain) merupakan unsur penting dari identitas pribadi dan sosial.

CAT menjelaskan proses bagaimana identitas dapat mempengaruhi perilaku komunikasi dalam bahwa individu termotivasi untuk mengakomodasi (bergerak menuju atau jauh dari orang lain) dengan menggunakan bahasa, perilaku nonverbal, dan paralanguage dengan cara yang berbeda.Sejauh mana komunikator merasa positif atau negatif tentang identitas mereka dapat diwujudkan melalui perilaku komunikasi. CAT juga mengusulkan berbagai jenis strategi akomodasi, konvergen dan divergen yang paling mendasar.

Divergensi mengacu pada cara di mana komunikator menonjolkan perbedaan antara mereka sendiri dan orang lain.Konvergensi adalah strategi dimana individu menyesuaikan perilaku komunikatif mereka untuk menjadi lebih mirip dengan lawan mereka, terutama yang mereka identifikasi.Untuk mengkomunikasikan identitas, ada beberapa hal yang perlu diperhatikan diantaranya perilaku nonverbal, Bahasa, Paralanguage, Aksen, dialek, idiom, panjang ucapan, dan semua varian fonologi

Divergensi atau konvergensi didorong oleh identitas kelompok. Mengingat bahwa komunikasi mungkin memerlukan nonverbal, bahasa, dan komponen paralanguage, anggota kelompok dapat menggunakan segudang ekspresi komunikatif. Dalam upaya untuk mempromosikan kekhasan mereka, kelompok yang memiliki identitas sosial yang positif lebih mungkin berbeda dalam pertemuan antargolongan dalam upaya untuk menunjukkan kekhasan mereka.Sebuah bentuk paling ekstrim dari kelompok mengkomunikasikan identitas positif mereka adalah kerumunan perilaku (memprotes, mendorong, berteriak). Demikian pula, kelompok subordinat dan yang dominan dapat menggunakan ethnophaulisms (slurs etnis) ketika mengacu pada outgroups dalam upaya untuk membedakan kelompok mereka dan mengkomunikasikan identitas sosial yang positif (Mullen, Rozell, \& Johnson, 2000).Tindakan komunikasi yang 
berbeda mengimplikasikan anggota kelompok merasa kuat tentang keanggotaan kelompok mereka, sehingga mereka bersedia untuk terlibat dalam konfrontasi fisik (susu\& Reicher, 1999). Sebaliknya, kelompok bawahan yang memiliki identitas sosial yang negatif cenderung untuk berkumpul dengan kelompok dominan (Giles \& Johnson, 1981). alokasi bias positif, diskriminasi terhadap outgroups ketika hasil melibatkan alokasi sumber daya positif (misalnya, uang atau pujian), adalah sebuah bentuk bias ingroup yang mengkomunikasikan identitas kelompok negatif bagi outgroup (Jackson, 1999).

Selain itu, ingroup anggota yang mencoba mempertahankan identitas kelompok yang positif melalui bahasa mungkin memiliki penghinaan bagi ingroup anggota yang mengadopsi bahasa outgroup.Mendapatkan bahasa outgroup juga dapat berkomunikasi identitas sosial negatif. Ketika Hogg, D'Agaca, dan Abrams (1989) menyelidiki persepsi anggota ingroup outgroup berbicara bahasa yang dominan, mereka menemukan bahwa semakin banyak orang yang diidentifikasi dengan ingroup budaya mereka, semakin besar kemungkinan mereka adalah untuk memiliki perasaan negatif terhadap sesama ingroupers yang berbicara kelompok dominan berbahasa. Penyesuaian aksen, dialog-

Kelompok mungkin menonjolkan aksen mereka untuk membedakan positif keanggotaan kelompok mereka, sedangkan outgroups yang memiliki identitas sosial yang negatif mungkin menipiskan aksen atau dialek dalam upaya untuk terlihat sama dengan kelompok dominan (Hurt, 1998). Icct, idiom, dan tingkat pidato dapat berfungsi dengan cara yang sama.Contoh-contoh ini semua mendukung gagasan bahwa akomodasi merupakan bentuk utama ekspresi identitas.

Namun, konsisten dengan klaim identitas yang subjektif, akomodasi individu akan bervariasi sebagai fungsi identitas ingroup dan vitalitas kelompok (Giles \& c Coupland, 1991).Terlepas dari tindakan komunikatif yang sebenarnya, akomodasi merupakan hal mendasar untuk konstruksi identitas. Meski begitu, sebagai anggota kelompok (baik itu bawahan atau dominan) mengakomodasi komunikasi 
mereka, mereka terus mempengaruhi, bentuk, membuat, dan menciptakan kembali identitas mereka. Ruang lingkup akomodasi, walaupun, dapat diperluas untuk mencakup elemen-retorik. Artinya, dialog harfiah, argumen, dan debat juga penting untuk identitas. dinamika intragroup Potensi sering diabaikan atau kesamaan antara anggota kelompok diambil untuk diberikan (lihat Oakes dkk, 1994.).teori SIT telah menempatkan penekanan pada persepsi sosial bersama di antara anggota kelompok. Namun, seperti Sani dan Reicher (1999) menjelaskan, dengan tidak termasuk dimensi retoris, kita exdudc kemungkinan bahwa anggota kelompok mungkin berbeda bahkan pada isu-isu inti seperti apakah sikap yang diberikan mendukung, merongrong, atau tidak relevan dengan esensi dari identitas kelompok(hal. 296). Dalam analisis mereka tentang perpecahan dalam Gereja Inggris yang disebutkan di atas, penulis ini menyoroti pentingnya elemen retoris dalam berkomunikasi identitas. Jelas, anggota Gereja Inggris memiliki konsep yang berbeda dari ch Mcntity $\mathrm{RCH}$, termasuk yang menghasilkan perpecahan antar anggota. Temuan ini menyoroti perhatian serius yang harus dibayarkan kepada proses retoris di mana kelompok terlibat.

\section{Penerapan CAT ala JTV}

Saat program berita Pojok Kulonan ditayangkan, penolakankemungkinan dari masyarakat Jawa Timur kecil, karena isi berita disampaikan menggunakan bahasa kromo halus, begitu juga berita Pojok Medhureh yang menggunakan bahasa baku Madura. Berbeda halnya jika Pojok Kampung yang tayang. Isi berita yang disampaikan menggunakan dialek khas Suroboyoan ini terkadang dianggap kasar dan tidak sopan.

Contoh narasi berita Pojok Kampung JTV seperti berikut :Enek kecelakaan awan mau. Korbane matek langsung, soale keplindes tur keseret truk nganti 500 meter. Polisi njlentrekke, awan mau enek wong tuwek mbambung matek kecemplung sumur. Mencermati dan mendengar kalimat dan bahasa di atas, bagi orang Surabaya sudah hal yang biasa. Tetapi bagi warga Jatim kulonan, kalimat diatas dianggap kasar dan tidak sopan. Hal ini terletak pada pemakaian istilah matek pada orang yang sudah meninggal dunia. Program berita Pojok Kampung telah 
tumbuh menjadi ikon JTV bahkan mendapat respons positif dari warga dengan rating yang cukup tinggi. Dan menyusul keberhasilan Pojok Kampung, pihak JTV mengembangkan program berita serupa dengan namaPojok Kulonan. Program ini menggunakan bahasa Jawa halus atau krama untuk merebut pemirsa Jawa Timur yang belum tergarap melalui program Pojok Kampung, serta Pojok Medhureh untuk pemirsa berbahasa Madura.Namun seiring waktu yang berjalan, serta program berita dengan berbeda versi akhirnya bisa membuat masyarakat Jawa Timur memahami hal tersebut,meskipun di awal tayang program Pojok Kampung pada Juli 2001, banyak mendapat kritikan dari masyarakat.

Gambaran mental yang ada dalam pikiran seseorang ketika mendengar aksen-aksen tertentu juga dipengaruhi oleh bagaimana stereotip yang ditampilkan media yang juga mempengaruhi persepsi penonton. Namun, budaya terkadang menganggapp perbedaan aksen sebagai cirri perilaku dan intelektual.misalnya karakterlambat yang diasoisasikan di daerah selatan dan aksen cepat Brooklyn.

Aksen merupakan variasi dalam pelafalan yang terjadi ketika orang menggunakan bahasa yang sama. Hal ini terkadang merupakan akibat dari perbedaan geografis dan historis. Contoh di Amerika Serikat, ada aksen selatan, New England atau New York. Sebagai tambahan dari variasi pelafalan yang menandai aksen, terdapat dialek yang dibedakan oleh perbedaan kosakata, tata bahasa dan tanda baca. Kemudian ada istilah slang yang menciptakan istilahistilah dalam situasi yang tidak formal, yang berfungsi sebagai cara untuk menandai identitas sosial atau linguistic. Slang dapat berdasarkan daerah, diasosiasikan dengan suatu subkultur atau digunakan kelompok yang terlibat dalam usaha tertentu.

Konvergensi yang dilakukan JTV tidak hanya melalui program berita. JTV juga menayangkan Film-Film Asing Boso Suroboyoan. Sesuai namanya, program ini menayangkan film-film luar negeri. Hanya saja, film-film itu disulih suarakan (dubbing) dengan bahasa Soroboyoan. Kedengarannya sangat lucu. Ada orang bule berbicara bahasa Jawa.Misalnya saja film Tomorrow Never Dies-nya James Bond. Bisa dibayangkan keunikan dan kelucuan agen rahasia berkejar-kejaran 
seru dengan para penjahat menggunakan bahasa Suroboyoan. Mandego koen! Lugurno pistolmu! (Berhenti! Jatuhkan senjata!, Red).

Contoh lain di film serial Love Talks bercerita tentang kisah cinta seorang profesional muda di Shanghai. Dalam satu adegan pda Love Talks, sang pemeran utama wanita tampak tidur dengan pulas. Sementara, sahabat prianya dengan gemas mencoba membangunkan si wanita itu dengan bahasa Suroboyoan. Hoi, tangio koen. Wis telat iki. Cepetan, iki jange ono acara iki (Hai, bangun. Ini sudah terlambat. Cepat, ini mau ada acara, Red).Tetapi, konsep itulah yang ditawarkan JTV lewat program Film-Film Asing Boso Suroboyoan-nya. Dialog-dialog khas Suroboyoan itu tampaknya memang menjadi ciri khas kuat film-film itu. Buktinya, sejak proses dubbing, film-film tersebut sudah menyedot perhatian. Dalam istilah Imawan, film boso Suroboyoan itu mampu membangkitkan kembali kegairahan dalam bekerja. Menurut Presiden Direktur JTV Imawan Mashuri, ini adalah sesuatu yang baru, lucu dan menyenangkan.Ini dirasakan terutama oleh para dubber yang mengisi suara. Memang, adegan-adegan film itu banyak sekali dipenuhi celetukan dan umpatan khas Suroboyoan. Tentu saja, kata-kata khas itu menjadi terdengar lucu. Karena, meluncur dari bibir bintang-bintang film Mandarin dan Barat. Tetapi, menjadi ciri karakter kuat film tersebut.

\section{PENUTUP}

Komunikasi yang terjadi antara orang-orang yang berbeda bangsa, ras, bahasa, agama, tingkat pendidikan, status sosial atau bahkan jenis kelamin disebut komunikasi antarbudaya (Mulyana, 2000).Manusia merupakanindividu dengan latar belakang budaya yang berbeda saling bertemu, baik secara tatap muka maupun melalui media komunikasi. Karena itu, ada beberapa faktor yang menyebabkan pentingnya komunikasi antarbudaya ini,

yang dapat dikatakan sebagai jembatan emas komunikasi antarbudaya.Budaya yang dihantarkan oleh televisi yang setiap hari hadir membawa budaya-budaya yang berbeda. Budaya-budaya inilah yang sering diserap oleh individu-individu dan melatarbelakangi tingkah lakunya sehari-hari dalam berinteraksi. Namun kenyataannya banyak manusia yang mengalami hambatan ketika mereka 
berkomunikasi antarbudaya.Sebenarnya hal inilah yang harus mendapat perhatian secara khusus bahwa orang berbeda budaya akan berkomunikasi secara berbeda pula. Hal ini untuk menjaga agar interaksi yang terjalin tidak terhambat. Kesulitan pertama adalah kecenderungan dalam melihat orang lain

Kesulitan yang lain, apabila mereka menganggap semua orang sama dengan anggota kelompok/etnisnya, biasa disebut stereotype. Sebenarnya manusia adalah makhluk yang unik, dengan kata lain, manusia memiliki karakteristiknya sendirisendiri. Maka, tidak semua perilaku komunikasi baik secara verbal maupun nonverbal mempunyai makna yang sama dalam semua budaya. Jadi, Setiap orang yang berkomunikasi antar budaya setidaknya bersikap terbuka terhadap perbedaan nilai, kepercayaan dan sikap; Dalam komunikasi antarbudaya kualitas kedekatan sangat penting agar memperkecil perbedaan; dan bersikap sensitif terhadap perbedaan ketika akan mengambil alih pembicaraan.Menempatkan diri pada posisi lawan bicara yang berasal dari budaya yang berbeda; bersikap spontan dan deskriptif; mengkomunikasikan sikap positif, menganggap berkomunikasi adalah kesetaraan, tetap percaya diri dan tenang dalam setiap situasi serta tidak sombong. Selain itu, isyaratkan empati dengan ekspresi wajah, gerak gerik yang penuh minat dan perhatian serta tanggapan yang mencerminkan pengertian (verbal dan nonverbal). Terakhir, tiap individuharus menyadari bahwa setiap orang punya andil dalam pembicaraan. Dengan demikian, hambatan yang ada dalam komunikasi antar budaya menjadi tiada.

\section{DAFTAR PUSTAKA}

Gudykunst, William B dan Bella Mody. 2001. Handbook of International And Intercultural Communication. Second Edition. Sage Publications. London Griffin, EM. 2000. A First Look At Communication Theory.Fourth Edition. McGraw-Hill, New York.

Littlejohn, Stephen dan Karen A Foss. 2008. Teori Komunikasi. Edisi 9. Penerbit Salemba Humanika. Jakarta. 
Morissan. 2008. Manajemen Media Penyiaran : Strategi Mengelola Radio dan Televisi. Penerbit Kencana. Jakarta

Mulyana, Deddy 1999, Nuansa-nuansa Komunikasi, Meneropong Politik \& Budaya

Komunikasi Masyarakat Kontemporer, Remaja Rosda Karya. Bandung.

Mulyana, Deddy. 2009. Komunikasi Antarbudaya Panduan Berkomunikasi Dengan Orang-orang Berbeda Budaya. Remaja Rosdakarya. Bandung.

Rivers, William L, Jay W Jensen dan Theodore Peterson. 2008. Media Massa dan Masyarakat Modern. Edisi Kedua. Prenada Media Grup. Jakarta.

Samovar, Larry \& Porter, Richard. 2010. Komunikasi Lintas Budaya. Edisi 7. Penerbit Salemba Humanika. Jakarta. 